\title{
“Cura- Malal”. Un ensayo del Servicio Militar Obligatorio en 1897
}

\section{“Cura-Malal". An essay of compulsory military service in 1897}

\author{
Santiago Garaño \\ Universidad Nacional de Tres de Febrero \\ Consejo Nacional de Investigaciones Científicas y Técnicas, Argentina \\ sgarano@hotmail.com
}

\section{Resumen}

En este trabajo nos proponemos describir y analizar la experiencia vivida en "Curá-Malal", el campamento cercano a Pigué donde se realizó la primera experiencia de conscripción obligatoria en el año 1897. A partir del análisis de dos libros que testimonian esa experiencia (uno escrito por un alto oficial y el otro, por un soldado), nos interesará reconstruir este primer hito, que fue fundacional en una genealogía del servicio militar obligatorio. La hipótesis que atraviesa este texto es que, si bien la normativa de creación es de 1901, hubo experiencias previas a la aprobación y reglamentación de esta ley, que han delineado las características centrales de esta institución. Por lo tanto, pensamos que es un aporte para historizar el proceso de creación de esta institución. Con fines analíticos, por un lado, retomaremos la bibliografía sobre el problema de la ciudadanía y la subjetividad. Y, por otro, revisaremos lecturas clásicas de la antropología sobre los ritos de paso y sobre los rituales, dando cuenta de las prácticas, rutinas y valores alentados por el personal militar y las transformaciones que produjo en la tropa de soldados.

\section{Palabras Clave}

Servicio Militar Obligatorio; Fuerzas Armadas; Soldados; Estado-Nación; Ciudadanía.

\begin{abstract}
In this work we intend to describe and analyze the experience lived in "Curá-Malal", the camp near Pigué where the first experience of compulsory conscription took place in the year 1897. From the analysis of two books that testify that experience (one of these written


by one senior officer and the other one by a soldier), we are interested in rebuilding this first milestone in a genealogy of the compulsory military service. The hypothesis that crosses this text is that, although the creation regulation is from 1901, there were previous experiences to the approval and regulation of this law, which have outlined the central characteristics of this institution. Therefore, we think it is a contribution to historicize the process of creation of this institution. For analytical purposes, on the one hand, we will return to the literature on the problem of citizenship and subjectivity. And, on the other hand, we will review classical anthropology readings about rites of passage and rituals, giving an account of the practices, routines and values encouraged by military personnel and the transformations it produced in the troop of soldiers.

\section{Keywords}

Compulsory Military Service; Armed Forces; Soldiers; National-State; Citizenship 


\section{Santiago Garaño}

\section{Introducción}

En el marco de la investigación que condujo a la elaboración de mi tesis doctoral, ${ }^{1}$ me interesó abordar una de las instituciones castrenses que considero central para comprender la importancia que tuvieron las Fuerzas Armadas (en adelante, FF.AA.) durante el siglo XX: el funcionamiento del servicio militar obligatorio en Argentina. Partía del supuesto de que estudiar la conscripción podía ser fundamental para estudiar las relaciones cívico-militares en su dimensión micro, local y cotidiana. Es decir, consideraba que su estudio podía iluminar la trama de relaciones tejidas entre oficiales, suboficiales y soldados en los cuarteles durante el período en que los conscriptos estaban "bajo bandera".

Recuerdo que la intuición de trabajar este tema se reforzó al leer los trabajos de Pilar Calveiro, en los que ella sostuvo que el poder desaparecedor que caracterizó a la última dictadura militar, hundía sus raíces en una vasta experiencia represiva de las FF.AA., cuya pieza central había sido el servicio militar obligatorio. ${ }^{2}$ En particular, Calveiro planteó que la conscripción tuvo un efecto diseminador de la disciplina en toda la sociedad argentina. Desde la perspectiva de esa politóloga argentina, se castigaba a los soldados por medio de la disciplina arbitraria y cruel, como parte de la instrucción, tomando como base el principio de aceptar órdenes más allá del carácter degradante y peligroso: "La convalidación social del orden, la jerarquía y la disciplina corre pareja con el odio hacia lo militar. Sin embargo, las anécdotas de cualquier reunión en donde los hombres que hicieron la conscripción obligatoria recuerdan las épocas de la 'colimba', en una última instancia se aprueba con una risa cómplice, acompañada de alguna expresión (¡qué bárbaro!), pero no de protesta, no de indignación (...) Es allí donde se graba la disciplina que impregnará el cuerpo de la sociedad. En ese derecho soberano que se reserva el superior para poner en juego la dignidad o la vida de otro, sin posibilidad de apelación". 3

Sin embargo, al reconstruir el estado del arte sobre la conscripción en Argentina, pude comprobar que se trataba de una institución poco explorada por las ciencias sociales y humanas, sobre todo teniendo en cuenta el hecho de que ha sido una experiencia muy significativa para amplios sectores sociales y que estuvo vigente durante casi todo el siglo XX. ${ }^{4}$ Los estudios sobre la conscripción se pueden agrupar en cuatro líneas: la primera, vinculada a la creación en 1901; ${ }^{5}$ la segunda, conformada por las denuncias sobre los más de 100 casos de conscriptos

\footnotetext{
${ }^{1}$ Garaño, Santiago. Entre el cuartel y el monte. Soldados, militantes y militares durante el Operativo Independencia (Tucumán, 1975-1977). Tesis doctoral, FFyL, UBA, mimeo, 2012.

2 Pilar Calveiro. Poder y desaparición. Buenos Aires, Colihue, 1998.

3 Pilar Calveiro, Política y/o violencia. Buenos Aires, Norma, 2006, p. 84.

${ }^{4}$ El servicio militar fue obligatorio desde 1902 hasta que el presidente Carlos Saúl Menem lo abolió en 1994, a raíz del asesinato del soldado Omar Carrasco, en Zapala. A partir de ese momento, se adoptó un sistema voluntario.

${ }^{5}$ Ricardo Rodríguez Molas. El Servicio Militar Obligatorio. Centro Editor de América Latina, Bs. As., 1983.
} 
desaparecidos durante la última dictadura y sobre cómo se los ocultó bajo la figura de "desertores"; ${ }^{6}$ la tercera analizó la experiencia de los soldados conscriptos que constituyeron el grueso de la tropa que combatió en la guerra de Malvinas, en 1982; ${ }^{7}$ y la cuarta, el caso del crimen del soldado Omar Carrasco y el fin del sistema obligatorio. 8

Como se puede ver, estos distintos estudios han abordado procesos relativamente excepcionales; mientras que el funcionamiento rutinario, cotidiano y burocrático de la conscripción es aún un área de vacancia para las ciencias sociales y humanas. De todas maneras, se ha dado por sentado que la conscripción operaba como el rito oficial de pasaje masculino a la adultez, a la ciudadanía y a la nacionalidad argentina; ${ }^{9}$ y que, desde sus orígenes, buscaba dar cohesión a la nueva república, reforzar el papel del Estado e inculcar una serie de valores nacionales y sociales a los jóvenes. ${ }^{10}$ Una de las motivaciones que tiene el presente trabajo es que considero que aún resta realizar trabajos históricos que les den fundamento empírico a esas afirmaciones generales sobre el rol que tuvo la conscripción durante gran parte del siglo XX.11

\footnotetext{
${ }^{6}$ Centro de Estudios Legales y Sociales. Conscriptos detenidos-desaparecidos. Buenos Aires, CELS, 1982. José Luis D'Andrea Morh. El escuadrón perdido. Buenos Aires, Planeta, 1998.

${ }^{7}$ Rosana Guber. ¿Por qué Malvinas? De la causa nacional a la guerra absurda. Buenos Aires, Fondo de Cultura Económica, 2001; De chicos a veteranos. Memorias argentinas de la guerra de Malvinas. Buenos Aires, Antropofagia, 2004. Federico Lorenz. Las guerras por Malvinas. Buenos Aires, Edhasa, 2006.

8 Mirta Mantaras. Caso Carrasco: un pacto de silencio. Neuquén, APDH, 1995; Rolando Silla. El poder de los humildes. La muerte del soldado Carrasco como ejemplo de drama y control social en Zapala. Tesis de licenciatura en Antropología, FFyL, UBA, mimeo, 1996.Jorge Urien Berri y Dante Marín. El último colimba. El caso Carrasco y la justicia arrodillada. Buenos Aires, Planeta,1995.Garaño, Santiago. "The Opposition Front against the Compulsory Military Service (FOSMO). The debate over conscription and the human rights activism in the post-dictatorship Argentina". En: Genocide Studies and Prevention 5: 174-190, 2010. Mirta Mantaras. Caso Carrasco: un pacto de silencio. Neuquén, APDH, 1995; Rolando Silla. El poder de los humildes. La muerte del soldado Carrasco como ejemplo de drama y control social en Zapala. Tesis de licenciatura en Antropología, FFyL, UBA, mimeo, 1996.Jorge Urien Berri y Dante Marín. El último colimba. El caso Carrasco y la justicia arrodillada. Buenos Aires, Planeta,1995.Garaño, Santiago. "The Opposition Front against the Compulsory Military Service (FOSMO). The debate over conscription and the human rights activism in the post-dictatorship Argentina". En: Genocide Studies and Prevention 5: 174-190, 2010.

${ }_{9}$ Rosana Guber. De chicos a veteranos...., Op. Cit., p. 67.

${ }^{10}$ Federico Lorenz. Las guerras por Malvinas, Op. Cit., p. 24.

${ }^{11}$ Desde su creación en la Argentina, la conscripción al mismo tiempo había jugado un rol en la configuración de sentidos de pertenencia -y exclusión- a la Nación argentina. Ser "hombre" y (por lo tanto) ser ciudadano argentino (hipostasiado en el fetiche de tener libreta de enrolamiento) eran condiciones que se obtenían gracias a cumplir con el "deber" del servicio militar (luego de haber sido declarado "apto"). A partir de haber (sobre)vivido a esa experiencia, se obtenía ese doble estatus. Sin embargo, otros jóvenes intentaron evadir el servicio militar de múltiples maneras: "zafar" en el sorteo; ser declarado "no apto" en la revisación médica; convertirse en "objetores de conciencia" (como fueron paradigmáticamente los testigos de Jehová). Otros, en cambio, buscaron, mediante el pago de una suma de dinero a autoridades militares o médicas, lograr "excepciones" o ser "acomodados"; es decir, aliviar la instrucción militar gracias a relaciones de amistad o cercanía con el personal militar. Entre otras razones, porque la conscripción se había convertido en un espacio donde los soldados muchas veces eran usados en tareas administrativas o domésticas de las autoridades militares (de ahí que se la llamara popularmente "colimba" -corre-limpia-y-barre-); porque la violencia estatal por parte de sus instructores estaba naturalizada; o simplemente debido a que era vista como una pérdida de tiempo para insertarse en el mundo laboral o continuar con los estudios.
} 


\section{Santiago Garaño}

Ahora bien, pese a los pocos estudios sobre esta institución castrense, es notable que la discusión de la ley de creación del servicio militar obligatorio en 1901 ha sido objeto de numerosas revisiones por parte de distintos investigadores. ${ }^{12} \mathrm{Sin}$ embargo, todos estos trabajos privilegian una mirada normativa, antes que una aproximación centrada en el abordaje de las prácticas, rutinas y los valores alentados por el personal militar. Es decir, se limitan a reconstruir y analizar la discusión de la llamada "Ley Ricchieri"- debido a que fue el Ministro de Guerra, Pablo Richieri, su principal defensor en el parlamento-, mientras que tanto su implantación - leáse, la encarnación en prácticas institucionales- así como las experiencias previas de conscripción no han sido analizados con la misma avidez.

Además, si bien en todos estos trabajos se toma esta ley como punto de partida, ni bien inicié el trabajo de archivos y bibliotecas militares pude comprobar 'otra' fecha de nacimiento para dicha institución. A diferencia de las pertenecientes al 'mundo civil', en mi trabajo de archivos en instituciones militares - como la Biblioteca del Círculo Militar y la del Estado Mayor del Ejército-, las referencias bibliográficas en ficheros y bases de datos me llevaron a "Curá-Malal", siempre considerada como la "primer conscripción argentina".

En el marco de la creciente tensión con Chile por problemas limítrofes, en 1897 el gobierno nacional decidió movilizar a la Guardia Nacional de la Capital Federal. Sin embargo, en esa oportunidad dispuso un nuevo mecanismo de reclutamiento: se convocó a la primera conscripción obligatoria de la que participaron los jóvenes de veinte años -previamente "enrolados"-, que durante dos meses convivieron "en campaña", donde fueron instruidos militarmente por parte de soldados "de línea" o "veteranos enganchados" por su propia voluntad y estuvo dirigida por Luis María Campos y Alberto Capdevila. El lugar elegido para instalar el campamento de instrucción fue Curá-Malal, ubicado a treinta y dos kilómetros de la ciudad de Pigué, en la provincia de Buenos Aires.

Este mecanismo de reclutamiento e instrucción se distinguía de los anteriores, que se habían basado en dos modalidades. Por un lado, la incorporación al Ejército de línea permanente de "enganchados" (es decir, contratados voluntariamente a cambio de una suma de dinero); "contingentes" (sorteados u obligados por la "ley de vagos"); "destinados" (infractores de las leyes de "enrolamiento" y ejercicios de milicias o Guardia Nacional); y, de ser necesario, "contingentes". Y, por el otro, la Guardia Nacional, integrada por varones argentinos de entre 17 y 50 años, cuyos integrantes formaban parte de la "reserva" del Ejército y sólo tenían obligación de asistir periódicamente a ejercicios de adiestramiento militar, bajo el mando de jefes civiles - convocados por el Gobierno nacional, en caso

\footnotetext{
12 León Rebollo Paz. "Antecedentes históricos de la ley sobre el Servicio Militar Obligatorio". En: Investigaciones y ensayos, 16, Buenos Aires, Academia Nacional de Historia, 153-176, 1974.Ricardo Rodríguez Molas. El Servicio Militar Obligatorio, Op. Cit. Miguel A. De Marco. "Organización, operaciones y vida militar", en Academia Nacional de la Historia, Nueva Historia de la Nación Argentina, Tomo V, 3a parte, Planeta, Buenos Aires, 2000.Augusto Golletti Wilkinson. "Servicio Militar Obligatorio - Ley Ricchieri de 1901". En: Actas del II Congreso Nacional de Historia Militar, 1999, Volumen II, 2001.
} 


\section{“Cura- Malal”. Un ensayo del Servicio Militar Obligatorio en 1897}

de situaciones de "conmoción interna" o "defensa nacional"-, siempre previamente sorteados y declarados físicamente "aptos". En este último caso, cabe aclarar que podían ser reemplazados por otro "voluntario" -denominado "personero"-, a cambio de abonarle una suma de dinero. ${ }^{13}$ A partir de esta reforma, la Guardia Nacional empezó a estar integrada por todos los ciudadanos que en 1894 hubiesen cumplido 20 años, quienes fueron obligados a realizar un período de instrucción militar de 60 días.

En este trabajo me propongo describir y analizar este primer hito en una genealogía del servicio militar obligatorio, como vía para historizar el proceso de creación de esta institución. La hipótesis que atraviesa este texto es que si bien la ley Ricchieri es de 1901, hubo experiencias previas a la aprobación y reglamentación de esta normativa, que han delineado las características centrales de esta institución. Es decir, que más allá de la aprobación de la normativa, no fue creada ex nihilo sino que hunde sus raíces en prácticas, lógicas y experiencias previas. A su vez, sostendré que esta primera experiencia de conscripción se revela como un 'hito fundante' del servicio militar obligatorio.

La reconstrucción pormenorizada de dicha experiencia se realizará a través de dos libros que testimonian el paso por el campamentos militar de "Curá Malal". El primer libro se llama En Curá-Malal. La División Buenos Aires. Primera Conscripción Argentina, y fue escrito por el Teniente Coronel Juan Amadeo Baldrich. ${ }^{14}$ Dedicado a los "camaradas" del Ejército, a los "jefes y oficiales" de la Guardia Nacional movilizados y a los "jóvenes conscriptos" de la División Buenos Aires, el texto recopila una serie de cartas publicadas en el Diario La Nación bajo el seudónimo de "Querandie". Este libro es una crónica de primera mano de la "primera conscripción argentina" que relata, entre las bromas y anécdotas varias, la cotidianeidad y la rutina diaria y semanal que organizaba la vida en el campamento; las prácticas de instrucción y de tiro en los polígonos; la alimentación (el llamado "rancho"); las características de topográficas y del clima (sobre todo, la dureza el invierno, los vientos, la lluvia y el frío y sus consecuencias para la instrucción militar que debía ser suspendida); la vida en las carpas, las excursiones a las sierras cercanas y los fogones; el estado sanitario de la tropa (y el énfasis en señalar los "pocos" casos de enfermos que "demuestra" la "resistencia" de la tropa movilizada).

Publicado en 1913, el segundo libro se titula Curá-Malal. Recuerdos de Campaña, y fue escrito por Julio Padilla, un ex conscripto y estudiante de medicina, que buscó "dejar constancia" de sus recuerdos "imborrables de campaña". Al decir del ex soldado, no tenía pretensiones literarias, sino que fue elaborado con el único fin de dejar una "prueba" del "cariño sincero y amistad profunda" a sus "compañeros de armas". Este libro está dedicado a sus "camaradas" de Batallón, "testigos fieles de todo lo bueno y de lo mucho malo que sufrimos y gozamos juntos".

\footnotetext{
13 Ricardo Rodríguez Molas. El Servicio Militar Obligatorio, Op Cit., pp. 13-15.

14 Tte. Coronel J. Amadeo Baldrich.. En Curá-Malal. La División Buenos Aires. Primera Conscripción Argentina. Buenos Aires, La Harlem Casa Editoral 1904.
} 


\section{Santiago Garaño}

En este trabajo, nos interesará crear un contrapunto entre las versiones de esa experiencia escritas 'desde arriba' (desde la oficialidad) y 'desde abajo' (desde la perspectiva de los conscriptos). Ello así debido a que estas dos perspectivas nos permiten el entrecruzamiento entre el proyecto institucional - los objetivos perseguidos y los medios para conseguirlos- y su encarnación en prácticas, sentidos y valores desde la perspectiva de los soldados conscriptos. Al mismo tiempo, consideramos que son memorias que no sólo permitieron dejar "constancia" a futuro de la experiencia vivida, sino también se volvieron relatos disponibles para ser presentada al resto de la sociedad, quien sostendremos que fue una de las audiencias destinatarias de este ritual.

En términos conceptuales, nos interesará explorar dos vías de análisis. Por un lado, daremos cuenta de la relación entre ciudadanía y subjetividad, a partir de los planteos realizados por Peter Corrigan y Derek Sayer en su trabajo acerca de cómo las prácticas, rutinas y rituales de las instituciones estatales han regulado las identidades sociales y las subjetividades de los ciudadanos en los Estado-nación modernos. ${ }^{15}$ De la perspectiva de estos autores, los Estados definen las formas aceptables de la identidad individual y colectiva así como también regulan gran parte de las formas de vida social consideradas legítimas: "las actividades del Estado, de manera más o menos coercitiva, 'alientan' algunas mientras suprimen, marginan, corroen o socaban otras [capacidades sociales humanas] (...). Clasificaciones sociales fundamentales, como la edad y el género, terminan sacralizadas en leyes, incrustadas en instituciones, rutinizadas en procedimientos administrativos y simbolizadas en rituales de estado". 16 En esta línea, las instituciones estatales llevarían a cabo un vasto proyecto de regulación moral a nivel de los sujetos y las poblaciones, es decir, totalizante e individualizante a la vez: un proyecto de normalizar, volver natural, parte ineludible de la vida, en una palabra 'obvio', aquello que es en realidad es arbitrario, cultural y, por ende, modificable.

Por lo tanto, a partir de un estudio de caso y de poner el foco en la conscripción como institución, en este trabajo intentaremos dar cuenta del peso material que las propias rutinas y rituales del Estado confieren a esas formas culturales consideradas legítimas. Además, nos interesará analizar cómo se forjaron una serie de modos de regulación que operaron no sólo mediante discursos, sino siguiendo a Corrigan y Sayer- centralmente en la combinación de las rutinas mundanas y de los rituales fastuosos. ${ }^{17} \mathrm{Y}$, en ese movimiento, cómo a través del paso de los jóvenes por dicha institución castrense, se ha construido un "mensaje de dominación", es decir, un 'mensaje moralizante' cuyo objetivo no es "de modo neutral, 'integrar la sociedad"' sino "imponer la dominación", normalizar, reconstruir las relaciones sociales a partir del forjado de identidades nacionales. ${ }^{18}$

\footnotetext{
15 Peter Corrigan y Derek Sayer. "La formación del estado inglés como revolución cultural”. En: Lagos, M. y P. Calla (comps.). Antropología del Estado. La Paz, Weinberg, 2007, p. 43.

16 Idem, p. 45.

17 Ídem, p. 45.

18 Ídem, p. 49.
} 
Por otro lado, finalizaré el trabajo retomando bibliografía antropológica sobre rituales y los ritos de paso, con el fin analizar las evidencias que presento en este trabajo: la reconstrucción del lento proceso de conversión en soldados que experimentan los conscriptos, a partir de una progresiva incorporación de rutinas, prácticas y disciplinas militares. Ello así porque consideramos que será iluminador de la doble dimensión que tuvo el servicio militar obligatorio: por un lado, coercitivo $\mathrm{y}$ violento, pero al mismo tiempo productivo de relaciones sociales, de identidades y de grupalidades.

\section{El nacimiento de la conscripción}

Un mes antes de ser "convocados", los futuros conscriptos se habían presentado en los cuarteles para inscribirse en la lista de los batallones que les correspondían y en los primeros días de abril de 1897 fueron citados al Cuartel de Palermo para que les entregaran los uniformes. A Julio le tocó el Segundo Batallón del Primer Regimiento de la Guardia Nacional de la Capital Federal.

Luego de que les ordenaran formar, Julio recordó que, "organizados a medias", empezó la primera instrucción militar: “...firmes ordenaron, y como por encanto, quedamos tan derechos que la compañía parecía [una] tabla, pues teniendo una idea tan errónea de la firmeza, se puede decir, que ni respirábamos siquiera". 19 A partir de este momento, se inició un lento proceso de aprendizaje de un nuevo uso del cuerpo: de estar "todo abatatado" en primer lugar aprendieron - gracias a un "trabajo fatigoso"- el "saludo en dos tiempos" y luego fueron sumando "medias vueltas", "marchas" y "contramarchas". Entre ejercicio y ejercicio, durante este primer día, por orden de jerarquía, "desde el Capitán hasta el cabo 1", todos y cada uno de los militares "pasaron listas" una y otra vez, hasta que se ordenó "romper filas".

Luego de un "toque de clarín", un capitán los hizo formar y les dieron utensilios necesarios para el "rancho". Una vez lavados los platos ("con mucha inexperiencia"), le distribuyeron el uniforme, conformado por un "kepie" ("genuinamente criollo"), la chaquetilla y pantalones, la colcha y los "botines patrios", y la ropa blanca - "más parecía uniformes para asilados que para soldados"y "se vistieron de" soldados: "Con el nuevo uniforme andábamos muy garbosos y consentidos en nuestra bella figura. Una vez que todos éramos soldados, nos considerábamos con el mejor derecho a ser amigos y así lo hicimos, siendo insoportable la algaraza que a cada aparición de un nuevo uniformado se producía. Era un titeo feroz". Julio recordó que, "Una vez listos, se pasó la última lista" y les dieron órdenes de presentarse al día siguiente a las 6 y media de la mañana y ya salieron "perfectamente formados" del cuartel. Al día siguiente cuando llegaron al

${ }^{19}$ Julio E. Padilla. Curá-Malal. Recuerdos de campaña. San Miguel de Tucumán, Imprenta A. Prebisch, 1913, p. 13. 


\section{Santiago Garaño}

cuartel, se multiplicaron las bromas entre ellos: se desconocían, eran ya 'otros', por estar vestidos con el uniforme y todos con el pelo cortado al ras:

"A las 7 formamos y cataplán, cataplán, marchen y descanso, no se oía más que un dos, un dos, muévase hombre; a dónde va, no salga de la fila; cállese la boca; no se ría, y para colmo nos empezaron a mandar al trote, march, un, dos, tres, cuatro, ah, ha! ...hasta que a las 9 nos llevan al cuartel más cansados...”. 20

Ese segundo día al mediodía les dieron "licencia" para visitar sus casas y, luego de pasar esa noche allí y almorzar a sus casas, volvieron al cuartel invadidos por la tristeza de separarse de su familia: “QQué sería de nosotros? ¿Y de nuestras madres? Ese fue el pensamiento común, ¡pobrecitas! ¡Ellas lloraban en sus casas por nosotros!". ${ }^{21}$ Según rememoró el ex soldado, esta progresiva separación de la familia, del hogar, les generaba una "melancolía" que se distinguía de la inicial alegría que había reinado entre ellos durante los primeros días. Como vemos en este relato, el paso de estar "vestido de soldado" a "convertido en un verdadero soldado" implicaría un lento aprendizaje de las jerarquías militares, de nuevas rutinas y prácticas corporales y de un lenguaje, una moral y sobre todo, una rígida disciplina bélica.

\section{El "vía crucis"}

Luego del toque de la "diana", cuando aclaraba, les entregaron el resto del equipo y el Mauser y les dieron una breve instrucción sobre cómo manejar el arma, hasta que les ordenaron que se prepararan para la marcha y "al compás de un alegre y entusiasta paso doble" llegaron desde Palermo hasta la estación de Sola, de donde salía el tren hacia Pigué. Esta "triunfal marcha" de conscriptos era tan agotadora físicamente que fue caracterizada por Julio tanto como un "Vía Crucis", frente a la gente que los despedía.

Cuando arribaron a la estación del tren, fueron despedidos por su familia y sus amigos: “¿Acaso sabíamos nosotros, ni sabía nadie, si volveríamos? ¡Nos llevaban para defendernos de los chilenos! ¡Esto era lo más seguro! ¡Qué triste era ver ese enjambre de jovencitos que tan animosos iban a inmolarse por su querida patria!". 22 Cuando arrancó el tren, trataron de reprimir la "angustia" - "por respeto al uniforme"-, entre vivas a la patria y muestras de afecto de sus familiares y amigos. Durante el viaje en tren, Julio cuenta que se conocieron casi todos los miembros de la Compañía y "simpatizaron mucho": "De modo que los que cuatro días antes no nos conocíamos casi, éramos tan amigos ya, como si nos ligara vieja amistad". 23

\footnotetext{
20 Ídem, p. 19.

21 Ídem, p. 21.

22 Ídem, p. 26.

23 Ídem, p. 29.
} 
Llegaron a Pigué a las doce y acamparon cerca de la Iglesia que estaba en construcción. Al aprendizaje de las rutinas militares, en el caso de Julio - y debido a su pertenencia de clase y al mundo universitario- se sumaban otros aprendizajes forzosos, como por ejemplo, lavar los platos. Pero, además, Julio detalló que fue llamado por un cabo para que junto a otros soldados fuera a buscar carne para la tropa y se dio cuenta de que "tenía que carnear": "¡nunca pensé que pudiera ser carnicero! ¡Por eso no estudié medicina!". ${ }^{24}$

Sin embargo, el ex conscripto consideraba que esta arrogancia - debido a su condición de estudiante universitario y de clase alta- implicaba una tensa relación con algunos superiores. Ese día un Teniente lo mandó a descargar el equipaje de los oficiales: "La gran perra (dije para mi interior) y a hacer de changador hijito, porque aquí si no lo haces lo que te dicen, te meten un plantón soberano". ${ }^{25}$ Con una "rabia sideral" y con su "cuerpo tan gordo", subió y bajó las valijas mientras los militares se reían de él: "era de destornillar de risa a los sinvergüenzas que me estaban viendo y me decían que cobre la changa". ${ }^{26}$ Según el relato de Julio, esa tarea fue encomendada por un oficial que, cuando se enteró que eran estudiantes universitarios, les "declaró la guerra a muerte" y los "martirizó".

Como podemos ver, a partir de ese momento, se inició el lento proceso de incorporación a las prácticas, rutinas y rituales que luego iba a caracterizar al servicio militar: Para el personal militar, se trataba de crear seres capaces de resistir no sólo la dureza de la vida castrense sino también a un régimen basado en el sometimiento al poder arbitrario de los superiores. En este sentido, incorporarse a la vida militar significaba ingresar a un mundo muy distinto a la vida civil: se trataba de un espacio donde se alternaba entre una estricta rutina, las prácticas de instrucción militar, pero también tareas de servidumbre.

Además, se trataba de un sistema de poder que se hacía ver, ${ }^{27}$ donde se representan las jerarquías que distinguían a soldados rasos del resto de personal militar, incluso de los soldados de la clase anterior (a los dominados de los dominantes). Por ejemplo, la subordinación a los superiores, se escenificaba no sólo en el trato cotidiano y en un uso estricto del lenguaje de las jerarquías, sino sobre todo, en los castigos y tareas domésticas a las que eran sometidos. Gracias a esas reglas de etiqueta -que exigían consentimiento, obediencia y subordinación- se efectuaba una puesta en escena de las relaciones de poder que organizaban la vida en el cuartel: Era un régimen que buscaba producir soldados (y sujetos) dóciles.

Parecía que, ya desde esta primera conscripción y en un contexto de conformación del Estado-nación moderno, el objetivo del Ejército argentino era crear una sociedad ordenada y controlada, a partir de la multiplicación y diseminación de la disciplina militar y los valores castrenses en todo el tejido social;

\footnotetext{
24 Ídem, p. 35.

25 Ídem, p. 36.

26 Ídem, p. 36.

27 Georges Balandier. El poder en escenas. De la representación del poder al poder de la representación. Barcelona, Paidós, 1994.
} 


\section{Santiago Garaño}

cuyo fin último era modelar la sociedad a su imagen y semejanza, como cuerpo disciplinado. 28

\section{El viaje hacia Curá Malal}

Al día siguiente se tocó la "diana" y lentamente todos empezaron a organizar las mochilas para el viaje hacia Curá Malal, bajo las órdenes del Coronel O’ Donnell y su Estado Mayor. De esta manera, Julio destacó que emprendieron la "marcha" sólo suspendida por unos breves descansos- todos "animados y contentos"; "pero la alegría no era más que un disimulado engaño para nuestros fatigados cuerpos". ${ }^{29}$ Poco a poco fue disminuyendo la intensidad de las conversaciones y se fue erosionando el "buen humor"; incluso algunos soldados cayeron rendidos de cansancio.

Por su parte, el Jefe de División, General Luis María Campos, fue a saludar a los "nuevos soldados". Según el recuerdo de Julio, el General se mostró "muy satisfecho con la resistencia de la tropa, haciéndonos cumplidos y justicieros elogios de nuestro entusiasmo" y -gracias a esa visita- recuerda que se sintieron más "animados" para la continuar la marcha hacia Curá-Malal. ${ }^{30}$ En este punto, podemos entrelazar el relato de Julio con el de Baldrich: el Teniente relató que el General Campos les daba "palabras de aliento, de felicitación y de cariño", en especial a algunos que venían "rezagados", debido al cansancio de marchar los 32 kilómetros que separaban Pigué de Curá-Malal, cargados con el equipo, armas y municiones. 31

Sin embargo, si bien los conscriptos no tenían "educación metódica" y Baldrich se sorprendió de que venían bien formados: "esforzándose cada soldado por parecer infatigable y bizarro, a pesar de la larga y no acostumbrada marcha que realizan. ¡Están lindos, están hermosos en su virilidad de veinte años los muchachos! Emociona verlos, jóvenes, fuertes, animosos, emulados y orgullosos y con derecho, ya que a los otros, a los que han faltado a esta cita del honor y del patriotismo les queda en gaje su lote de vergüenza". ${ }^{32}$ En cambio, Julio consideró que, al interior del colectivo de conscriptos, se delineaban dos grupos: "algunos de estos muchachos protestaban en cinco clases de idiomas, tener 20 años y maldecían al benemérito 75, otros patrioteros ultras, pedían todo el rigor de la ley para los que se burlaban de ella y no obedecían ni a los ímpetus de su conciencia que les ordenaban cumplir con su deber; y otros (...) no daban señales de vida....".33

Finalmente, los conscriptos llegaron al lugar donde se iba a emplazar el futuro campamento - "nuestra futura mansión"- y el desfile de las tropas fue

\footnotetext{
28 Pilar Calveiro. Poder y desaparición, Op. Cit., pp. 11 y 13.

${ }^{29}$ Julio E. Padilla. Curá-Malal..., Op. Cit., p. 41.

30 Ídem, p. 44.

31 Tte. Coronel J. Amadeo Baldrich.. En Curá-Malal. La División Buenos Aires. Primera Conscripción Argentina. Buenos Aires, La Harlem Casa Editoral 1904, p. 32.

32 Ídem, p. 33.

33 Julio E. Padilla. Curá-Malal..., Op. Cit., p. 20.
} 
recibido por la música de la diana "que los despertó (...) del aletargamiento y postración a que el cansancio nos redujo". Según el recuerdo del ex soldado, la llegada fue "imponente" y "ese saludo de músicas marciales nos quitó el sufrimiento. Nos sentíamos nuevos...". ${ }^{4}$ En ese momento se distribuyeron en carpas (insuficientes para todos) y, como pudieron, intentaron dormir, rendidos por el sueño, pero imposibilitados por el frío y hambre.

En una de las primeras cartas, el Teniente Baldrich les contó a los lectores del Diario La Nación cómo eran las características topográficas del lugar donde se iba a hacer la "primera conscripción argentina": "Es una localidad admirable desde el punto de vista sanitario y sobre todo del punto de vista militar, por la clase de instrucción característicamente de montaña, que permite dar a la tropa. Nuestra infantería, de llanura por tradición, se hará alpinista...". 35 Es decir, frente a los conflictos por las fronteras con Chile, era necesario modificar la modalidad de la instrucción militar del Ejército y su tropa y - para el oficial del Ejército- se basaba en las "necesidades que puedan sobrevenir en un país de fronteras tan complejas desde el punto de vista topográfico". Este "terreno" iba a colaborar en el proceso de 'templar' "el espíritu decidido de los nuevos soldados, animados de tan altos sentimientos patrióticos que retemplan a los viejos veteranos". Sin embardo, la aspiración de Baldrich es que tuviera un efecto multiplicador en el resto de los argentinos: “... en pocos días más esto será un Babel, pero sin confusiones ni de lenguas ni de sentimientos: la patria y el deber serán nuestros dioses lares y la fuente de inspiración que agitará con soberbias palpitaciones, el corazón de diez mil argentinos, congregados bajo la bandera sagrada del Pasaje y Castañares!" 36

\section{Las pruebas y el sufrimiento}

Un primer hito, luego de la llegada al campamento de Curá-Malal, es el relato de los "sufrimientos y privaciones" que vivieron durante los primeros días de campaña. Si bien el hambre, la escasez de carpas y el cansancio poco a poco se fue normalizando, Julio le atribuye otro sentido a estos "sufrimientos" y "privaciones": "La precipitación y la falta de elementos de transporte fue el obstáculo de esta campaña. Así y todo debemos agradecerla. Porque precisamente esas privaciones y sufrimientos nos formaron militares y nos unió más estrechamente a los que las compartimos". ${ }^{37}$

Con una interpretación similar, para Baldrich dichas adversidades no sólo operaban como un elemento cohesionante del grupo - que los unía "más estrechamente"-, sino como una serie de 'pruebas' que los formaban como militares, que "moldeaban esta soberbia creta de los soldados": "La Guardia Nacional, a pesar de que no tiene mucho de lo que necesita y se le debe dar, y que vendrá, resiste,

\footnotetext{
34 Ídem, p. 45.

35 Tte. Coronel J. Amadeo Baldrich. En Curá-Malal..., Op. Cit., p. 24.

36 Ídem, p. 24.

${ }^{37}$ Julio E. Padilla. Curá-Malal..., Op. Cit., p. 48.
} 


\section{Santiago Garaño}

parece tallada en bronce, y espera sin murmurar, lo que se le dice que vendrá y aún no llega. Aparece virtuosa y estoica". ${ }^{38}$ Es decir, la deficiencia en la provisión de alimentos, carpas y otras facilidades en la campaña se volvían parte del conjunto de 'pruebas' que se requerían para forjar la "resistencia", la "virtuosidad" y el "estoicismo" de la tropa de conscriptos.

Este tipo de 'pruebas' también nacían de la intrínseca "unión" que se tejía entre "naturaleza" y el "hombre" que parecían - para Baldrich - "cantar la belleza y la fecunda virilidad de la vida y la patria". 39 Por ejemplo, al igual que para Julio, Baldrich consideraba que las inclemencias del tiempo - sobre todo la lluvia- eran otras "pruebas" que demostraba la capacidad de "resistencia" de la tropa movilizada:

"Pero no mata ni entumece el nervio de la muchachada: la vena se mantiene tensa y las risas, las causeries, las escenas, los hombres, las cosas todas de esta gran familia militar, veterana y movilizada se comentan y se cuentan. Es un caudal inagotable y cálido, lleno de color local y de nacionalidad; vigoroso, móvil, inquieto y picarezco, en cuyo fondo siempre lleno de luz, se destaca el carácter típico de la raza, tan admirablemente homogénea, a pesar de los elementos de tan diversa línea étnica que la constituyen". 40

Sin embargo, para las autoridades militares, el mayor desafío de esta experiencia de conscripción era construir una "gran familia militar" entre los "veteranos" y la tropa "movilizada", a partir de compartir un espacio de instrucción militar, pero también de sociabilidad masculina. "Sufrir y gozar juntos" era una forma de transformarse en soldados, pero también de hacerse argentinos. En este sentido, según relata Baldrich, el nacimiento de la conscripción obligatoria presentaba el desafío de contar con una población diversa - "el corazón de diez mil argentinos"- que debía homogeneizarse y lograr que no hubiera "confusiones ni de lenguas ni de sentimientos", a partir de la activa producción de una serie de valores y representaciones de corte bélico y nacionalista, pero también intensas emociones y sentimientos.

\section{El comienzo de la instrucción y de la "transformación"}

Con el paso de los días, desde la perspectiva de Julio, "la vida se normalizó": el campamento se trasladó unos 200 pasos del lugar original; se dio la orden de que los "clases" durmieran separados de los soldados y se les entregaron las colchonetas; se normalizó el correo y la llegada de los diarios; y la instrucción fue progresando; se fueron configurando rutinas diarias y semanales que organizaban la vida en la

\footnotetext{
38 Tte. Coronel J. Amadeo Baldrich. En Curá-Malal..., Op. Cit., p. 37 y 38.

39 Ídem, p. 24.

40 Idem, pp. 101 y 102.
} 
campaña. Para el ex soldado, esta normalización implicó el "cese de los sufrimientos".

Por su parte, según informaba Baldrich a los lectores del diario La Nación, Curá-Malal ya se había convertido en la "casa" de los movilizados, una "Ciudad Blanca" que combinaba - junto a la calidez de ese nuevo y transitorio "hogar" -, la rigidez y el orden de la vida militar. ${ }^{41}$ Con la llegada de la última brigada al campamento, "la máquina de Curá-Malal tiene todas sus piezas y está funcionando homogénea, sin rozamiento ni perdida de calor y por consiguiente de fuerza. Un mes más y la división será una formidable masa veterana, con sus 8959 hombres de tropa, presentes, 24 cañones Krupp, 1500 caballos, parque, intendencia, sanidad y demás servicios auxiliares". ${ }^{42} \mathrm{Al}$ decir de Baldrich, se trataba de una nueva "máquina" que - gracias a su funcionamiento a la perfección- iba a "moldear" una División de soldados hasta convertirlos en una "formidable masa veterana".

Poco a poco se fue configurando la rutina en el campamento. El lunes se inició la instrucción de los soldados movilizados: por la mañana se dictaban cinco horas diarias sin armas en terreno, y la tarde era el tiempo de la instrucción teórica de las clases y oficiales. Baldrich destacaba que "el espíritu de las tropas en este campamento se mantiene tenso, se entona día a día y toma en los nuevos soldados la contextura y el temple que caracteriza a los veteranos" y saludaba "la resistencia moral y el vigor físico de que dan muestra nuestros noveles veteranos". ${ }^{43}$ Como vemos, este proceso de construcción de los "noveles" en "veteranos" se asentaba en una rígida disciplina militar: "Se ve, pues, que el tiempo no será derrochado y que en puridad de verdad, no quedará libre más que el absolutamente necesario para comer y dormir: se hará vida intelectual y física activísimas, siendo digno de notarse que nadie protesta de esta fajina; nadie la encuentra pesada la tarea ni dura la prueba a que todos son sometidos, bajo el severo control del generalísimo".44

Luego de varios días, comenzó la instrucción con armas de fuego. Según rememoró Julio, les costó poco recordarlos porque seis meses atrás había sido la última movilización a la que habían concurrido.

Sin embargo, un punto de conflicto se generó entre los conscriptos y los veteranos, encargados de instruirlos militarmente. Si bien los "veteranos" los "hostilizaban de todos modos" - a lo que sumaba un claro prejuicio de clase- y esto les despertó el odio hacia ellos, Julio destacaba que nunca se quejaron con sus superiores de los soldados de línea - o "chafes"- sino que más bien eran motivos de "risa y de escarnio". Además, Julio planteaba una oposición - ¿una frontera?- entre quienes iban "gustosos" a cumplir un "deber patriótico" y quienes se movían por el "interés", el dinero, la "conveniencia" ("Nosotros cumplimos una ley: íbamos

\footnotetext{
${ }^{41}$ Idem, p. 55.

42 Idem, p. 98.

${ }^{43}$ Idem, 44.

${ }^{44}$ Idem, p. 78.
} 


\section{Santiago Garaño}

gustosos a servir a la Patria: ellos eran enganchados o contratados por interés, por su conveniencia").

Por su parte, Baldrich destacaba otra finalidad para ese encuentro entre los soldados "contratados y enganchados" y "conscriptos". La diferencia entre los conscriptos (definidos como "niños") y los "viejos soldados" habilitaba un espacio de transmisión de experiencias intergeneracional en el que el "espíritu disciplinado y el temple y la soltura marcial del veterano se inocula vigorosamente en la muchachada, ávida de aprender y emulada por la gente de línea de arma".

"Mientras hablan los milicos de línea escuchan sonrientes o graves a los niños, y estos a su vez rodean al viejo soldado y oyen embobados y mudos, relatos de pasadas campañas, de sufrimientos indecibles, de abnegaciones sublimes y de glorias calientes y avasalladoras. Los muchachos se entusiasman, proyectan batallas y campañas quiméricas; organizan ejércitos...”. 45

Es decir, Baldrich destacaba los "lazos de simpatía y compañerismo" nacidos entre la "tropa de línea y la movilizada", que "se estrechan hora a hora" y revelan "elevado sentimiento de varonil sinceridad". Por lo tanto, para este oficial del Ejército, la "primera" conscripción era un encuentro -por momentos tenso- entre dos tipos de reclutamiento; entre dos tipos de ejército; entre varias generaciones; entre "niños" y "veteranos". Y permitía, desde su perspectiva, no solo la instrucción sino también la transmisión de experiencias bélicas anteriores, de la "moral" guerrera y la "disciplina" militar "de eterna fuente" así como la posibilidad de tejer lazos de "compañerismo" entre estos grupos:

"Hay en la tropa un espíritu de fraternidad, de compañerismo admirable: veteranos y milicianos son todos uno. Aquí no se dice guardia nacional, no se conoce el vocablo, desde que todos, soldados, oficiales y jefes de una y otra clase, se estiman y consideran iguales. Las pequeñeces han desaparecido y no hay sino una cosa, una idea grande y noble: la patria y el deber, que a todos emula sin rivalidades personales que depriman la majestad soberana del cuadro y la severa compostura de los personajes". 46

Si pensamos las críticas a los soldados encargados de la instrucción como una forma de impugnar esa jerarquía entre "niños" y "veteranos", Julio también recordaba la lenta conversión en "veteranos", gracias a la adquisición de destrezas militares, en particular la práctica de tiro ("lo más importante que había en nuestro programa de maniobras"):

${ }^{45}$ Idem, 45.

${ }^{46}$ Idem, p. 158. 


\section{“Cura- Malal”. Un ensayo del Servicio Militar Obligatorio en 1897}

"Nos asimilamos de tal modo a la vida militar que nos gustaba enormemente. En estos días se recibe la noticia de los arreglos con Chile. Casi les puedo decir que nos desagradó- estábamos dispuestos a pelear y aprendimos con ansias todo el mecanismo militar, y luego nuestra vida de soldados tan llena de encantos, de alegrías. Esas reuniones nocturnas, imborrables y divertidísimas. En fin todo ya estábamos hecho unos veteranos y empezamos a sentir la pena dejar aquella". ${ }^{47}$

En la misma línea, Baldrich enfatizaba la eficacia del proyecto de los oficiales que buscaba "modelar" a la tropa de jóvenes ("como la creta del escultor, están prontas para ser modeladas como lo exija el país que es el ideal de todos"), de operar una verdadera "transformación" en la juventud argentina, gracias a la instrucción militar:

“...uno se pregunta sorprendido qué secreto poder han podido alcanzar esta transformación, esa adaptación maravillosa de esa juventud que parecía destemplada, flácida, sin ideales levantados e impracticables por la ausenta de virtud patricia; y qué resorte extraño ha podido ser tocado para vincular en días, de tal modo, a los viejos soldaros y encariñarlos mutuamente. Hay que ver a estos camaradas a la hora del rancho nocturno. Es una gran familia de hermanos que se congrega al amor de la lumbre para reparar las fuerzas perdidas, encauzar en una grande y potente corriente los sentimientos de solidaridad y de destino que los agita y soñar en común con sacrificios de antemano aceptados y con triunfos que parece atados a su suerte, de tal modo que los creen seguros y posibles. La misma naturaleza (....) parece predisponer los espíritus de todos y prepararlos para la ruda vida en campamento (...) el alma de estos jóvenes soldados debe sentirse exaltada por todo lo grande y sublime que es capaz de inspirar la patria, que se presiente amenazada por peligros que la imaginación agiganta". 48

Esta "transformación" ("los muchachos practicaban los mismos ejercicios que los veteranos") se había operado gracias a la instrucción militar. En este sentido, la División ya fuera otra: "Éramos soldados de verdad, bastante disciplinados, instrucción aprovechada, por la tarde formaba el Batallón para la lista y luego todos nos reuníamos al mando del comandante- para la gran lista mayor. Era de oír aquel: 'Para defender la Patria' que contestaba una sola voz de todos los soldados cuando se decía 'subordinación y valor'”. ${ }^{49}$ En la misma línea, Baldrich destaca los efectos que había tenido esta primera experiencia de conscripción:

"iQué diferencia entre los primeros días de la movilización y los presentes! La división es otra; los reclutas de entonces no sé dónde están!” destacando “...el estado militar de estas tropas, animadas de tan alto espíritu marcial; tan bizarras, tan

\footnotetext{
${ }^{47}$ Julio E. Padilla. Curá-Malal...., Op. Cit., p. 89.

48 Tte. Coronel J. Amadeo Baldrich. En Curá-Malal..., Op. Cit., pp. 46 y 47.

${ }^{49}$ Julio E. Padilla. Curá-Malal..., Op. Cit., p. 56.
} 


\section{Santiago Garaño}

hermosas, tan llenas de fuerza y virilidad, de disciplina y abnegación, si Vv. Quieren! (...) el milagro es cierto, tangible y entonces en la plenitud del convencimiento de hecho, me invade una sensación suprema de satisfacción, de orgullo, como si todo esto fuera mi obra, mi porvenir, mi vida entera. (...) Dos meses más de campaña, y la división, intachable como instrucción, sería brillante...". ${ }^{50}$

Como vemos, si bien esta "transformación" de la tropa movilizada mostraba la progresiva incorporación de la moral, disciplina castrense y de los valores nacionalistas, también se fundaba en una experiencia de socialización masculina. En este sentido, esta "transformación" era tanto el fruto tanto de la "proximidad" entre los compañeros y camaradas - y jefes y soldados "veteranos-, como de la lejanía de su familia de origen.

\section{Las horas de "vagancia y asueto"}

Como se puede observar, fue en este marco de incorporación de una disciplina castrense, en el que se empezaron a tejer lazos de "amistad" y "compañerismo" entre los conscriptos, basados en compartir esa esa experiencia que alternaba la instrucción militar con un espacio de socialización entre jóvenes, que incluía el humor y la diversión, experiencia que implicaba "sufrir y gozar juntos". En este sentido, si Curá -Malal fue una experiencia de conscripción altamente significativa fue debido a estos 'otros' espacios de socialización, que se daban de modo paralelo a la mera instrucción militar. Por ejemplo, después de la instrucción, conscriptos y militares pasaban el tiempo en los fogones y en las carpas. En esos momentos de "vagancia y asueto", Julio y el resto de los conscriptos se convertían en "pebetes" y buscaban los "medios necesarios de divertirnos lo bastante, para hacernos olvidar el frío y la campaña". 51

Uno de los principales espacios de socialización eran los "fogones", que se hacían una vez terminado el "rancho" y la limpieza de manos, platos y jarros. Julio se enorgullecía de su pertenencia al "fogón de los Ingleses" - el "más duradero", "la más alta institución en Curá-Malal"- y del que participaban "amigos" de todas las Compañías que se conocían de la Ciudad de Buenos Aires (y "los que recibían más encomiendas"). En las sobremesas "largas y entretenidas", se dedicaban a comentar el "trato" que recibían en los batallones y mientras señalaban su "gratitud" a "sus" jefes y oficiales, "sus" superiores, ("estuvimos bien mandados") y criticaban a algunos de "nuestros" oficiales que "fundados en uno o dos galones, trataban como perros a muchachos". Al mismo tiempo, Julio destacaba que estos "matones" eran "bien conducidos por sus colegas": "Nunca expresamos una queja, porque estaba al frente del nuestro un distinguido jefe, que no permitía la menor represión injusta y cuando se aplicaba correcciones o castigos inmerecidos, a los que lo hacían se les

${ }^{50}$ Tte. Coronel J. Amadeo Baldrich. En Curá-Malal..., Op. Cit., pp. 157 y 158.

${ }^{51}$ Julio E. Padilla. Curá-Malal..., Op. Cit., p. 87. 
volvía la oración por pasiva, porque el comandante entendía su deber y se hacía respetar como debía". ${ }^{52}$ Antes que la "queja", Julio prefería otros mecanismos de impugnación y reversión de las jerarquías, como la "risa y el escarnio".

\section{Los últimos días}

El General Capdevilla le comunicó al General Campos que el presidente dispuso que "la división completa baje a la Capital Federal para ser revistada por él antes de su disolución". En ese marco, Julio consideró que los últimos días hasta la partida, el 8 de junio, se pasaron rápidamente. El último día Julio fue "licenciado" por el Coronel, que le agradeció por los "servicios prestados".

El campamento de Curá-Malal parecía "las ruinas de Pompeya" y se reunieron en los fogones "y nos despedíamos de ellos con dolor porque fueron nuestros alegres compañeros en las penurias pasadas". A las cuatro de la mañana se tocó la última diana de Curá-Malal y al amanecer, desarmaron las carpas, acomodaron sus mochilas y sus pertenencias y se quemaron las colchonetas en una gran fogata. El Regimiento era la cabeza del resto de la Brigada, que lo esperaban "correctamente formados" y a las ocho partieron en una "silenciosa" marcha hacia Pigué y le dieron una "cariñosa despedida" de "nuestro refugio de 60 días".

A diferencia de lo que había sucedido cuando arribaron y como resultado de la transformación que se había operado "en campaña", en la marcha de regreso "con toda felicidad", "nadie se cansaba" y cada paso "nos recordaba la venida", acompañados por tragos de ginebra, whisky y caña, y casi sin agua - ya que "bebidas espirituosas que son más necesarias para la marcha": Se 'sentían otros' ("nos creíamos viejos soldados"). De esta manera, a las 2 de la tarde llegaron a Pigué "que engalanado nos recibía", "perfectamente formados y lo más arrogantes":

"Al dejar Curá-Malal parece que nos quedaba algo del corazón en esas sierras queridas. Jamás olvidaremos esa época feliz de la vida en que fuimos muchachos inexpertos para volver soldados formados. Allí se aprendió disciplina y trabajo; allí pasamos horas de angustias y de penas nostalgias de cariños lejanos, allí sufrimos pero allí aprendimos a saber cómo se lucha para vencer, como se trabaja en la vida. Allí conocimos la amistad verdadera. Allí nuestro espíritu se retempló y supimos prácticamente cómo se quiere a la bandera, cómo se hace respetar y cómo se la hace respetar". 53

Pasaron un día en Pigué y, en el regreso en tren, en todas las estaciones fueron recibido "como héroes" con "discursos patrióticos y vivas a los muchachos que se repetían incesantemente". Llegaron en la estación de Sola a la 6 de la mañana y empezaron la "marcha". A las siete, hicieron "nuestra entrada a la gran Metrópoli,

52 Ídem, p. 85.

53 Julio E. Padilla. Curá-Malal.., Op. Cit. p. 119. 


\section{Santiago Garaño}

que vestida de gala nos esperaba para darnos el abrazo de gratitud y satisfacción" y los conscriptos marchaban "con un porte y una marcialidad que daba gusto". ${ }^{54}$ Según el recuerdo de Julio, cuando llegaron a la avenida Santa Fe "ya era fastidiosa la aglomeración" y, de hecho, les dificultaba la marcha. Ya en cuartel en Palermo "rompieron filas" y la gente que se agolpaba en las puertas para verlos, pudo ingresar y le brindaron la "más cordial bienvenida". Pasaron toda la tarde rodeados de sus familiares y esa noche, entre mate y mate, alternaron "con la limpieza de botones, botines y vestuarios para estar relativamente aseados para la revista".

\section{La gran revista militar}

Desde el "alba" de ese domingo, empezaron los preparativos para la "Gran Revista Militar". A las 8 y media emprendieron la marcha hacia el centro de la ciudad "a tomar el sitio que nos correspondía". El Presidente de la Nación, con el Estado Mayor y el Ministro de Guerra, recorrieron la "línea" y luego empezó el desfile, acompañado por la gente que los vivaba y les tiraba flores a su paso:

"Nosotros marchábamos emocionadísimos. Todo Buenos Aires estaba en las calles, desde el Presidente de la República hasta el pobre jornalero. Todos nos enviaban sus aplausos y nos arrojaban flores y nosotros recogíamos en nuestras almas estremecidas de gratitud esos aplausos y esas flores para depositarlas a los pies de esa Matrona Venerada que se llama República Argentina. A nuestra patria eran dirigidas por nuestro intermedio". 55

Baldrich destacó que la Guardia Nacional era una especie de "encarnación de la Patria", "correcta, severa, hermosa", que contrastaba con la "multitud" del público presente: "El tono, la gama clara de los uniformes de las tropas, contrasta con los colores múltiples del pueblo. [Sin embargo] Aquello es una sola masa, una sola raza, una sola alma. Todos son argentinos. Se siente la patria, se la ve, se la toca: ¡qué hermosa, que fuerte y qué gloriosa a un tiempo!". 56

En ese espacio en el que el "pueblo", el Ejército y la Guardia Nacional "fraternizaban", se buscaba consolidar a la "patria", como un colectivo homogéneo ("una sola masa, una sola raza, una sola alma"). Esto nos permite ver la instrucción militar de los jóvenes conscriptos como actos ejemplares dirigidos al resto de la sociedad: la experiencia de conscripción de los jóvenes de 20 años, se convirtieron en 'mensajes moralizantes' que buscaron influir -gracias a un efecto metonímico- a la totalidad de los ciudadanos argentinos y exhibir la "prueba" de las virtudes militares, de la encarnación en los jóvenes argentinos de una moral guerrera, masculina, disciplinada y uniformada.

\footnotetext{
54 Ídem, pp. 124 y 125.

55 Ídem, p. 127.

${ }^{56}$ Tte. Coronel J. Amadeo Baldrich. En Curá-Malal..., Op. Cit., p. 17.
} 
Cuando regresaron al Arsenal, los esperaba el "bravo" Gral. Campos "sin poder dominar las lágrimas rebeldes que no oían sus voces de mando y caían como gotas de rocío sobre su casaca veterana" y se despidieron de O'Donnell y "todos los que nos mandaron": "Entregamos los pertrechos, los camaradas nos dimos el adiós, siguiendo cada uno su camino, abrazándonos tiernamente prometiendo no olvidarnos, y al ver a los jefes gritamos: Viva la patria, Viva el General Campos, Vivan nuestros jefes, Viva el 6 de línea". ${ }^{57}$ Por último, volvieron a sus casas, luego del abrazo con sus "compañeros y hermanos de Campaña" y fueron "recibidos con las caricias de los nuestros". En palabras de Baldrich:

"Bienvenido sea este despertar del civismo que ha sacudido a cuatro millones de argentinos en tal día y en tal momento! Es como una nueva era. Démosle paso y marchemos con esas columnas nacionales, ayudando a los que flaqueen con el ejemplo de los más fuertes. Son los varones de los primeros días. Raza de soldados con alientos de atletas; retoño vigoroso de la encima secular de mayo. ¡Cuánta vida en sus rostros hermosos y marciales, y cuánto vigor en sus miembros, tallados sobre el molde viejo!".58

Además, esta ceremonia ritual implicaba el final exitoso de ese proceso de "instrucción" militar: al haber completado ese ritual de paso, estos jóvenes se habían convertido en soldados considerados legítimos para las autoridades militares, con el sello de la aprobación oficial. A su vez, nos muestra que la conscripción tenía una doble faceta: una moralizante y otra de poder disciplinario, coercitivo y violento. ${ }^{59}$ Es decir, implicaba tanto el uso explícito de la fuerza como el encauzamiento y la domesticación de las conductas y de las costumbres: la conscripción pretendía operar como un ritual violento que transformaba niños en adultos; cuya eficacia radicaba en convertirlos en ciudadanos argentinos y en varones adultos, gracias a la internalización de la disciplina castrense, de los valores del "orden", el "respeto" y la disposición al "sacrificio" en nombre de la "patria".

\section{Palabras finales}

En este trabajo se realizó una reconstrucción de la "primera conscripción argentina" en la que jóvenes "aptos" de veinte años convivieron "en campaña" y recibieron instrucción militar durante sesenta días en el campamento de CuraMalal, en el año 1897. A partir del testimonio de un ex conscripto y de un Teniente Coronel, hemos visto cómo esta experiencia 'piloto' cimentó una moral masculina

\footnotetext{
57 Julio E. Padilla. Curá-Malal..., Op. Cit., P. 128.

58 Tte. Coronel J. Amadeo Baldrich. En Curá-Malal..., Op. Cit., p. 16.

59 Sofía Tiscornia ha estudiado cómo los edictos policiales y el poder de policía se caracterizan por este doble carácter moralizante y coercitivo violento. Tomo esta idea para pensar la función de la

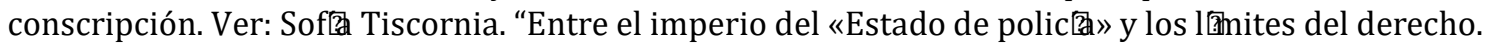
Seguridad ciudadana y polic魚 en Argentina”, en Nueva Sociedad. 191: pp. 78-89, Caracas, 2004.
} 


\section{Santiago Garaño}

guerrera, construida gracias a la convivencia profunda "en campaña" y operó múltiples transformaciones en las subjetividades de los conscriptos.

Además, esta primera conscripción puede ser pensada como un ritual particularmente propicio para que el Ejército pudiera poner en escena y dramatizar una serie de valores fundamentales para el flamante Estado-nación, tales como la "lealtad", el "valor", el "sacrificio" y sobre todo el "compañerismo" y la "camaradería". Sin embargo, lejos de apelar meramente a rutinas, rituales y valores morales (a la disciplina militar), la eficacia radicó en la producción de fuertes vínculos de lealtad, así como de intensas emociones y sentimientos que aunaron a la tropa de soldados conscriptos con los "viejos soldados". Para ello, no sólo las autoridades militares buscaron la imposición de una disciplina bélica, sino que esta instrucción militar fue paralela a la generación de espacios de socialización entre militares y civiles. Como cierre de este 'rito de paso, también se hizo un gran puesta en escena del final exitoso del ritual, cuya audiencia fue la sociedad porteña.

Por lo tanto, en función de los materiales analizados, consideremos que esta primera experiencia de conscripción tuvo dos caras: por un lado, como un ritual de paso, cuyos destinatarios fueron los soldados conscriptos; y, por otro, como un ritual más amplio, cuyas puestas en escena tuvo una audiencia mayor, la sociedad porteña. Para ello, recurriré a dos tipos de bibliografias antropológicas sobre los rituales.

En primer lugar, siguiendo a la literatura clásica sobre ritos de paso producida por la antropología británica, se puede pensar a los conscriptos como seres liminales, atravesando un momento de transición ("ni en una serie ni en otra"), es decir, viviendo un rito de pasaje que suponen un cambio de estado, posición social y/o edad. ${ }^{60}$ En Pureza y Peligro, Mary Douglas señala que, por medio de los ritos, las sociedades crean y controlan la experiencia y se generan los sentimientos necesarios para que los sujetos se mantengan fieles al papel que deben desempeñar: "El rito es creador de mundos armoniosos, con poblaciones ordenadas que desempeñan sus respectivos roles. ${ }^{61}$ Desde este marco de análisis, el nacimiento de la conscripción obligatoria presentaba el desafío de homogeneizar una población diversa - "el corazón de diez mil argentinos"-, con el fin de que no hubiera "confusiones ni de lenguas ni de sentimientos". A partir de una separación entre el campamento y el hogar de los conscriptos; de la intensa "proximidad" entre los compañeros y camaradas, sus jefes y superiores y los soldados "veteranos"; de la "distancia" con la "vida ordinaria"; se fue configurando "otro hogar". Gracias a la normalización de la vida en campaña y el cese de los "sufrimientos", se buscó construir una "gran familia militar" entre los "veteranos" y la tropa "movilizada" marcada por la rigidez, el orden y las jerarquías militares- a la vez que configurar y homogeneizar el "carácter" de ciudadanía masculina.

Además, hemos visto los múltiples procesos de transformación que se operaron durante la experiencia de conscripción: el paso de estar "vestido de

\footnotetext{
60 Victor Turner. El proceso ritual. Estructura y antiestructura. Madrid, Taurus, 1988.

${ }^{61}$ Mary Douglas. Pureza y peligro. Un análisis de los conceptos de contaminación y tabú. Madrid, Siglo XXI, 1973, p. 101.
} 
soldado" a "convertido en un verdadero soldado"; de ser "niños" a "veteranos". El campamento de Curá-Malal se convirtió entonces en una "máquina" que buscó "modelar" a la tropa de soldados movilizados hasta convertirlos en una "formidable masa veterana". Estas transformaciones -gracias a la instrucción militar-implicaban un lento aprendizaje de las jerarquías militares, de nuevas rutinas y prácticas corporales y de un lenguaje, moral y disciplina bélica y de transmisión de experiencias bélicas previas. Sin embargo, en este proceso de transformación fueron centrales los espacios de socialización donde se tejieron lazos de "amistad" y "compañerismo" entre los conscriptos y sus jefes, basados en compartir la misma experiencia. El sufrimiento, la privación y la disciplina castrense operó como un elemento cohesionante del grupo - que los unía "más estrechamente"- así como una serie de 'pruebas' que los formaban como militares. "Sufrir y gozar juntos" era una forma de transformarse en soldados, pero también de hacerse argentinos. Sin embargo, junto a la instrucción militar, otros espacios de socialización de "diversión" y de "placer" coexistían con la rigidez de la vida y la formación militar.

En segundo lugar, también nos parece fértil explorar la propuesta del antropólogo brasilero Roberto Da Matta, ${ }^{62}$ quien invita a pensar los rituales como instrumentos que permiten expresar los mensajes sociales con mayor claridad que en la vida cotidiana y rutinaria. ${ }^{63}$ En el caso analizado en este artículo, si bien en la vida cotidiana de las FF.AA. se hablaba permanentemente de "sacrificio", "lealtad", "compañerismo", este ritual puso en foco estos valores y relaciones fundantes del mundo militar. Sin embargo, como afirma Roberto Da Matta, lo hizo expresando esos tópicos con más fuerza, con más vehemencia, coherencia y conciencia y, sobre todo, dotándolos de una fuerza emocional y moral.

Entonces, si consideramos que los rituales son discursos sobre la realidad en los que se destacan con más fuerza que en la vida cotidiana ciertos aspectos críticos y esenciales para un determinado grupo social, ${ }^{64}$ podemos descifrar una serie de mensajes que se pusieron en escena allí. Para comenzar, como ya hemos visto, la principal audiencia receptora de este discurso era la propia tropa, que experimentó el paso por la conscripción a partir de una experiencia cargada de fuertes emociones y sentimientos, a partir de la cual se forjaron vínculos de lealtad muy potentes entre militares y civiles. En este sentido, esta experiencia de conscripción reveló que, a la par de la dimensión represiva de la disciplina militar, una dimensión productiva en la constitución de identidades y lealtades grupales.

Sin embargo, cuando regresaron del periodo "en campaña", se hizo una gran puesta en escena cuya audiencia fue la sociedad argentina, en la que se buscó

\footnotetext{
62 En su trabajo sobre los tres modos básicos de ritualizar en el mundo brasilero (el carnaval, el desfile militar y la procesión religiosa), Da Matta sostiene que los rituales son los mecanismos fundamentales utilizados para dramatizar el mundo, es decir, discursos sobre la realidad en la que se destacan ciertos aspectos (al tiempo que se ocultan otros) y, por lo tanto, que expresa y refleja de maneras múltiples y complejas la estructura social.

63 Roberto Da Matta. "Você Sabe com Quem Está Falando?". En: Carnavais, Malandros e Heróis. Rio de Janeiro, Zahar Editores, 1979 [2002], p. 94.

64 Ídem, p. 77.
} 


\section{Santiago Garaño}

dramatizar la exitosa conversión que habían realizado este conjunto de jóvenes, transformados en hombres adultos, ciudadanos argentinos y soldados, a partir de la incorporación de la disciplina castrense. A su vez, con este tipo de potentes mensajes, se buscaba reforzar y cimentar la relación entre las FF.AA. y la sociedad civil, aunque también dramatizando que el Ejército era el depositario de los valores morales de la flamante Nación argentina.

\section{Bibliografía}

Alan Morinis, (1985). "The ritual experience: pain and the transformation of consciousness in ordeals of initiations", en: Ethos. 2, vol. 13: pp. 150-174.

Arnold Van Gennep. Los ritos de paso. Madrid, Taurus, 1986 [1909].

Augusto Golletti Wilkinson. "Servicio Militar Obligatorio - Ley Ricchieri de 1901". En: Actas del II Congreso Nacional de Historia Militar, 1999, Volumen II, 2001.

Centro de Estudios Legales y Sociales. Conscriptos detenidos-desaparecidos. Buenos Aires, CELS, 1982.

CONADEP. Nunca más. Informe de la Comisión Nacional sobre la desaparición de personas. Buenos Aires, EUDEBA, 1985.

Esteban Krotz. “Antropología, derechos humanos y diálogo intercultural”, en Revista de Ciencias Sociales. 103-104: pp. 75-82, México DF, 2004.

Federico Lorenz. Las guerras por Malvinas. Buenos Aires, Edhasa, 2006.

Georges Balandier. El poder en escenas. De la representación del poder al poder de la representación. Barcelona, Paidós, 1994.

Jorge Urien Berri y Dante Marín. El último colimba. El caso Carrasco y la justicia arrodillada. Buenos Aires, Planeta,1995.

José Luis D’Andrea Morh. El escuadrón perdido. Buenos Aires, Planeta, 1998.

Julio E. Padilla. Curá-Malal. Recuerdos de campaña. San Miguel de Tucumán, Imprenta A. Prebisch, 1913.

León Rebollo Paz. "Antecedentes históricos de la ley sobre el Servicio Militar Obligatorio". En: Investigaciones y ensayos, 16, Buenos Aires, Academia Nacional de Historia, 153-176, 1974. 
Mary Douglas. Pureza y peligro. Un análisis de los conceptos de contaminación y tabú. Madrid, Siglo XXI, 1973.

Miguel A. De Marco. "Organización, operaciones y vida militar", en Academia Nacional de la Historia, Nueva Historia de la Nación Argentina, Tomo V, 3a parte, Planeta, Buenos Aires, 2000.

Mirta Mantaras. Caso Carrasco: un pacto de silencio. Neuquén, APDH, 1995.

Peter Corrigan y Derek Sayer. "La formación del estado inglés como revolución cultural”. En: Lagos, M. y P. Calla (comps.). Antropología del Estado. La Paz, Weinberg, 2007.

Pilar Calveiro. Poder y desaparición. Buenos Aires, Colihue, 1998.

Pilar Calveiro. Política y/o violencia. Buenos Aires, Norma, 2006.

Ricardo Rodríguez Molas. El Servicio Militar Obligatorio. Centro Editor de América Latina, Bs. As., 1983.

Roberto Da Matta. "Você Sabe com Quem Está Falando?”. En: Carnavais, Malandros e Heróis. Rio de Janeiro, Zahar Editores, 1979.

Rolando Silla. El poder de los humildes. La muerte del soldado Carrasco como ejemplo de drama y control social en Zapala. Tesis de licenciatura en Antropología, FFyL, UBA, mimeo, 1996.

Rosana Guber. ¿Por qué Malvinas? De la causa nacional a la guerra absurda. Buenos Aires, Fondo de Cultura Económica, 2001.

Rosana Guber. De chicos a veteranos. Memorias argentinas de la guerra de Malvinas. Buenos Aires, Antropofagia, 2004.

Santiago Garaño, "The Opposition Front against the Compulsory Military Service (FOSMO). The debate over conscription and the human rights activism in the postdictatorship Argentina". En: Genocide Studies and Prevention 5: 174-190, 2010.

Santiago Garaño, Entre el cuartel y el monte. Soldados, militantes y militares durante el Operativo Independencia (Tucumán, 1975-1977). Tesis doctoral, FFyL, UBA, mimeo, 2012.

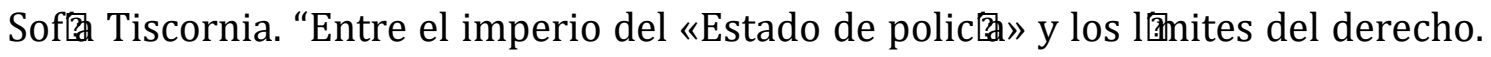
Seguridad ciudadana y polic通 en Argentina”, en Nueva Sociedad. 191: pp. 78-89, Caracas, 2004. 


\section{Santiago Garaño}

Stuart Hall y David Held. "Ciudadanos y ciudadanía", en Constalaciones de la Comunicación. 1: pp. 224-237, Buenos Aires, 2000.

Tte. Coronel J. Amadeo Baldrich.. En Curá-Malal. La División Buenos Aires. Primera Conscripción Argentina. Buenos Aires, La Harlem Casa Editoral 1904.

Veena Das. Sujetos del dolor, agentes de dignidad. Bogotá, Universidad Nacional de Colombia, 2008.

Victor Turner. El proceso ritual. Estructura y antiestructura. Madrid, Taurus, 1988.

Recibido: 08/09/2016

Evaluado: $27 / 10 / 2016$

Versión Final: 24/11/2016 